PAEDIATRIC LESSONS FROM THE PAST

\title{
John Darwall MD: Birmingham's forgotten children's physician
}

\author{
A N Williams, J Reinarz
}

Arch Dis Child 2005;90:60-65. doi: 10.1136/adc.2004.050088

John Darwall's (1796-1833) contribution to medicine has not attracted the attention it merits from medical historians. Although the Birmingham physician died at a relatively young age, his work in several fields of early nineteenth century medicine, including paediatrics, deserves to be both recovered and addressed, if only due to the light it sheds on medical practice in England during the first decades of the nineteenth century. Given its pioneering nature, his work on occupational health has attracted some attention, albeit minor.' However his contribution to the development of paediatrics, as represented by his most substantial publication, Plain Instructions for the Management of Infants (1830), has been completely ignored by historians of child health. This paper seeks to redress this particular oversight.

See end of article for authors' affiliations

\section{Correspondence to:} Dr A N Williams, Child Development Centre, Northampton General Hospital, Northampton NN1 5BD, UK; anw@ doctors.org.uk

Accepted 22 April 2004 $\int \mathrm{t}$ ohn Darwall was born in 1796 at Deritend, at the lower industrial end of Birmingham near the River Rea, where his father was chaplain of St John's Chapel and a master of the Free Grammar School. Placed under his father's care at the school at the age of 8, Darwall undertook a medical apprenticeship between 1813 and 1816 with George Freer (1770-1823), a surgeon to the General Hospital, Birmingham, as well as founder of the Orthopaedic Hospital, Birmingham, who achieved a certain degree of renown as a result of his work on aneurism. ${ }^{2}$ After completing his period of indenture in 1816, Darwall went to London to attend hospital rounds and several courses of lectures, including those of the influential surgeon John Abernethy (17641831), whose work at St Bartholomew's is to have helped turn surgery from a craft to science. By May 1817, Darwall sat his exams and became a member of the College of Surgeons. However, not content with the "superficial manner" in which medicine was taught in London, the young surgeon proceeded to Scotland the following autumn to continue his medical education. ${ }^{3}$ Having originally travelled to Edinburgh in order to learn physic, which he studied under Professor James Gregory (1753-1821), Darwall also studied with the anatomists Alexander Monro III (1773-1859) and John Barclay (1759-1826) and attended Gordon's (1786-1818) lectures on physiology. Provided with letters of introduction to a number of celebrated practitioners, Darwall was a particularly studious pupil, neglecting both exercise and rest, to his own detriment. According to his friends, reading in various libraries is said to have strained his health, which he never again completely regained. After the winter of 1818, he briefly returned to Birmingham, to become an assistant to his former master, Freer.

Darwall returned to Edinburgh in 1819 determined to take his doctor's degree. In 1821, he completed his formal education, presenting his thesis, entitled De Morbis Artificum (fig 1). Darwall's thesis (a short work, comprising only 23 pages) was not only concerned with the diseases of artisans, but it concentrated primarily on those affecting the health of inhabitants in Birmingham, which in the period of half a century had been transformed from the "toyshop of Europe" into the first industrial town, its population approaching 100 000. Clearly inspired by what he had seen while Freer's young medical apprentice in Birmingham, his thesis ranks as one of the earliest dissertations on the subject of occupational health, predating Charles Turner Thackrah's work in the field by exactly a decade. Unlike his own apprenticeship, the conditions of child labour were much harder. Contemporary perceptions regarding children's living and working conditions are best illustrated by the celebrated "slavery of children" cartoon of Cruikshank of around 1833 (see fig 2).

After graduating from Edinburgh, Darwall returned to Birmingham and was elected physician to the General Dispensary at Union Street, a post he held for 10 years until his death. His master George Freer had predeceased him by a decade. Interestingly, according to John Conolly (1794-1866), a fellow student and pioneer in the field of mental health who introduced nonrestraint to Hanwell asylum in Middlesex, Darwall's letters produced in the years immediately following his return to Birmingham suggested "depression of mind", perhaps due to the slow growth of his medical practice. ${ }^{4}$ His heavy schedule was equally commented on by contemporaries. At times, Darwall is to have prescribed for more than 80 charity patients in a single morning. In particular, he was noted for his keen powers of observation, using both the stethoscope and percussion to make his diagnoses. First described by Laennec (1781-1826) in 1819, the stethoscope was relatively new to medical diagnosis, and, to his contemporaries in Birmingham, Darwall must have appeared very much like Tertius Lydgate, the hero of George Eliot's Middlemarch (1871-72), whose promotion of this "new fangled foreign toy" divided his village. ${ }^{5}$ An interest in botany also led 


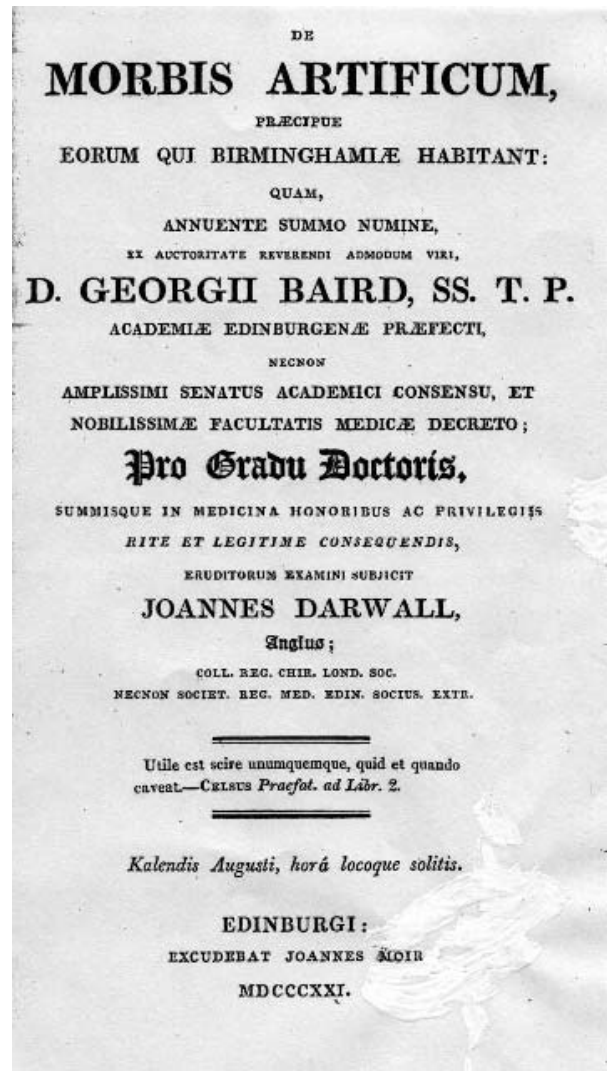

Figure 1 De Morbis Artificum.

Darwall to first use a microscope in 1827 and introduce botanical subjects to his medical lectures.

Interestingly, Darwall wrote an early history of medicine for the Society of Useful Knowledge and became progressively more attracted to medical journalism given the slow growth of his private practice. For a time he was joint editor (with the Worcestershire physician and founder of the Provicial Medical and Surgical Association Dr Charles Hastings (1794-1866)) of the Midland Medical and Surgical Reporter, to which he contributed articles on dropsy, spinal and cerebral irritation, and the medical topography, or early public health of Birmingham. In particular, the first piece, that on dropsy, betrays his conservative approach to illness by suggesting that "operations are the disgrace of the medical art". $^{6}$ According to Darwall, surgical interventions were justifiable only "when no relief can be afforded without them". ${ }^{7}$ His more well known essay on spinal and cerebral irritation essentially took this a step further by calling the attention of practitioners to the ways in which the nervous system affected bodily functions, including the circulation of the blood and respiration. ${ }^{8}$ Though occasionally resorting to bleeding and the application of blisters with good effect, Darwall stressed the moral management of patients, whether faced with toothache or the early stages of insanity, ideas that may have come from his friend and colleague, John Connolly.

\section{DARWALL THE MAN}

From his youth, and following family tradition, Darwall had been carefully instructed in religion. Unlike many medical students of his generation and after, he never played cards, was indifferent to music, and fastidious as to the society of women. It is even stated in a memorial produced by a fellow student that he first entered a public ballroom in $1824 .{ }^{9}$

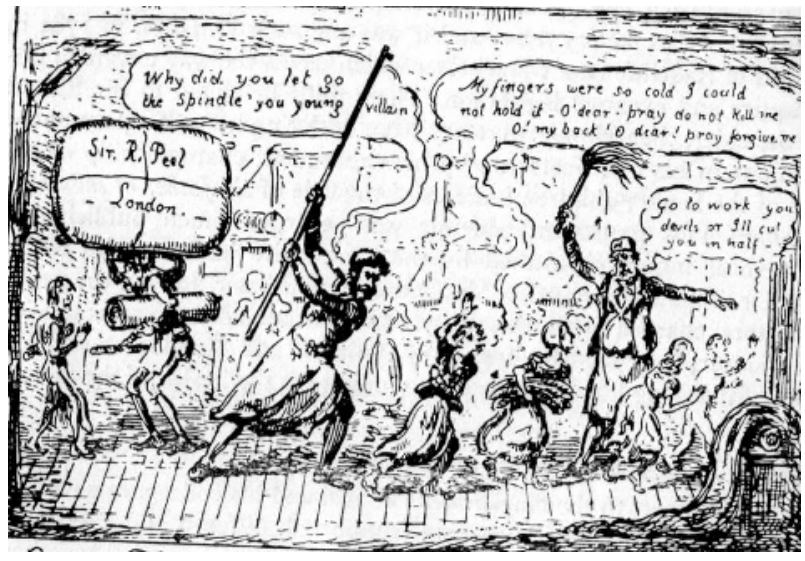

Figure 2 Engraving from "The condition of the West Indian Slave contrasted with that of the infant slave in our English Factories" by Robert Cruikshank, published about 1833 by W. Kidd, London.

Against these odds, he eventually married in 1821 and had two daughters by his wife, Mary. Despite choosing a medical career over a religious one, he remained committed to his spiritual beliefs. The book in which he carefully recorded all medical fees, for example, closed each year with a Latin prayer. ${ }^{10}$ It was also stated that he had a strong distrust of popular leaders and an intense contempt for quacks. Furthermore, it is claimed that he ceased to frequent newsrooms in later life as any reflection on the state of the country at the time of the Reform Bill greatly distressed him. ${ }^{11}$

\section{PLAIN INSTRUCTIONS FOR THE MANAGEMENT OF INFANTS}

In 1830, Darwall published his most comprehensive text. The work contains practical observations on the disorders incident in childhood to which was added his previously published essay on spinal and cerebral irritation. Based on chapter titles alone, it includes sections on the management of children, deformities, rules for applying medical remedies in early life, cutaneous diseases, affections of the digestive

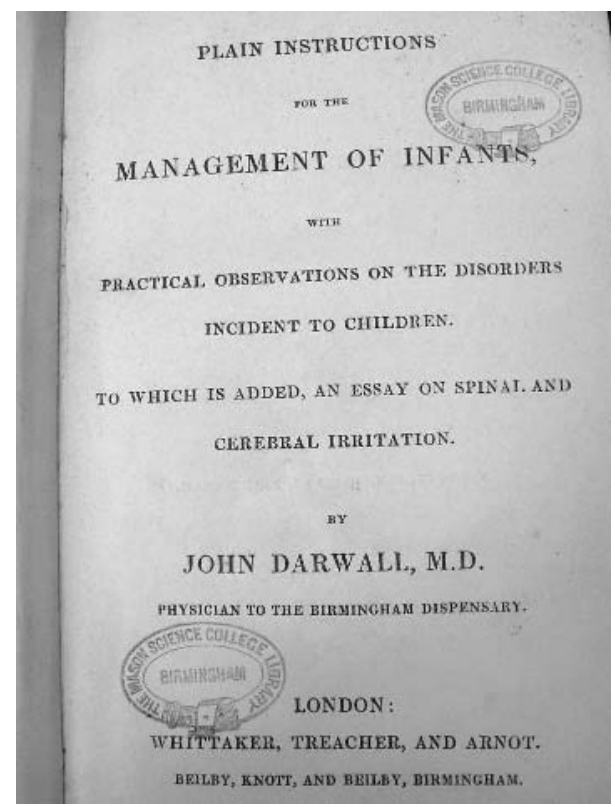

Figure 3 Plain instructions for the management of infants. 
organs, dysuria, and respiration. It also addresses chronic and acute hydrocephalus, convulsions, as well as a description of childhood stroke.

Darwall's book was clearly intended for the profession, including nurses, and endeavoured to educate readers through the use of plain and intelligible language.

The text supports the education of the public in medical matters, for "[i]t is only while they [the public] are ignorant that they will tamper: give them knowledge and they will fear, where before they rushed blindly forward". ${ }^{12}$ The preface, in particular, gives advice that remains valid and strikes a strong chord with the modern medical reader.

"Whoever has had much experience in the diseases of children must have witnessed errors arising on the one hand from too much daring, and on the other from too much anxiety". (Preface) ${ }^{12}$

Though meant primarily for other medical practitioners, the work's language is accessible and challenges the "popular prejudices" of the nursery. ${ }^{13}$ Rather than teach mothers to treat their own children, however, Darwall desired that they learn the lessons of prevention. He strongly advocates breast feeding, endeavouring to keep the newborn's needs within the state of nature. He recommends that "the child be put on the mother's breast as soon as the mother has recovered from the immediate exhaustion of labour". ${ }^{14}$ Furthermore, he suggests that, prior to the onset of dentition, a child's diet ought to consist of the mother's milk alone. The prolonged intervals between pregnancies as a consequence of breast feeding are also recognised, as is the origin of rickets, said to be due to "deficient nutriment" (p. 16). ${ }^{12}$ In this he is following in the footsteps of William Cadogan's famous Essay upon nursing and the management of children, published in $1748 .{ }^{15}$ The work of historians has also shown the prevalence of such ideas throughout this period. ${ }^{16}$

Not surprisingly, given Darwall's long services to the Birmingham Dispensary, he emphasises the direct relation between poverty and increased childhood mortality.

\section{"There can be however no question but that a much greater number of the children of the poor die under seven years of age, than those of the rich: nor can there be less a question that cold, and the effects of cold, are the principal causes of this mortality ... It must however be acknowl- edged that there are other sources of the mortality of children among the poor besides cold: perhaps the management of this class is in every respect calculated to diminish health"}

By arguing along these lines, Darwall can be seen to have advocated ideas similar to those expressed only a few years earlier by John Bunnell Davis, the founder of London's Universal Dispensary for Children (1816). In any case, his published text was very much like that of Bunnell, for, like the early dispensary, it was intended to inform other medical practitioners, while simultaneously attempting to teach parents the importance of infant management. ${ }^{17}$ The connection between poverty and health was eventually popularised and entered the popular imagination in the 1840s with the appearance of works by sanitarians such as Edwin Chadwick (1800-90), Thomas Southwood Smith (17881861), and even Fredrich Engels (1820-1895).

Unlike his medical colleagues, Darwall advocated a theory of the functioning healthy body based on a very localised knowledge of anatomy and physiology, ideas that built on the tissue pathology of the French surgeon Xavier Bichat (17711802), another medical practitioner who died tragically young. Like earlier practitioners and his more vocal contemporaries, such as the medical journalist Thomas Wakley (1795-1862), he was scathing towards the quacks of his age. His attitude regarding alternative medical practitioners strikes an additional chord today.

"Galvanism much recommended in the paralysis of children but it has not preserved its reputation and is now almost abandoned to charlatans". (p. 155) ${ }^{12}$

The fact that galvanism was still practised at the Birmingham Dispensary, suggests Darwall's criticisms may at times have been veiled attempts to reform the medical practices of his colleagues. ${ }^{18}$ Nevertheless, such critical views should hardly surprise today's audience considering that Darwall practiced in those years immediately preceding the passage of the 1858 Medical Act. Moreover, this was a period that witnessed the growing importance of observation in medicine, an approach that was developed largely by surgeons in France, who directly sought out the signs of pathological anatomy, thereby sweeping away earlier humoral conceptualisations of disease. Consequently, though Darwall's work shares many similarities with those produced by a previous generation of doctors, it also depicts the first signs of some important transformations in nineteenth century medical practice.

\section{"We every day are told of remedies by unprofessional persons which have cured this or that disease, sometimes a disease which, like true consumption, we know to be utterly beyond the power of medicine: and this unques- tionably arises from inaccurate observation. Those symp- toms are noticed in which diseases resemble each other, not those in which they differ". (Preface) ${ }^{12}$}

When reading this book one feels that Darwall, like many other practitioners who were making greater use of clinical material in these years, spoke from considerable practical experience in the management of children.

"Children differ so much in natural constitution, in temperament, and in vigour, that no two can be managed exactly in the same way". (Preface) $)^{12}$

Clearly, not an advocate of clinical protocols in the modern sense, Darwall emphasised the importance of regular clinical examination, ideas that surely developed during this training in Edinburgh, where a systematic course of clinical lectures had be designed in the late eighteenth century to "teach the practice of physic by examples": ${ }^{19}$

"In all the disorders of children it is necessary to watch, with the utmost vigilance, every change, nor will any medical man properly consult his own reputation who does not see infants, who suffer under acute disease, twice or three times per day, and more particularly while they are asleep. This may seem to the friends unnecessary, and it may seem so in many cases to the medical attendant himself: yet, by neglecting it, symptoms may in the intervals of his visits have so rapidly come on, as to render all future assistance useless". (p. 167) ${ }^{12}$

Although not drawn from Darwall's book, this image shown in fig 4 represents the more severe type of patient who would have been treated in the Orthopaedic Hospital, where he was appointed a physician in 1831 . 
In a chapter entitled "Deformities", Darwall comments on the management of club feet. He cites his success if "treatment is attempted by rolling and sometimes by the addition of slight splints depending upon the deformity". ${ }^{20}$ His management of strawberry marks is more decisive:

"The only certain cure, however, is their removal by the knife. The sooner this is done the first month from birth the better-the less mark will be left afterwards and the less danger will arise from haemorrhage ...". (p. 28) ${ }^{12}$

He also recommends that vaccination be used to remove these tumours, but that "it cannot be entirely depended on" (p. 28). ${ }^{12}$ Like his other claims, which were based on thorough observation, this one was the result of observing nearly 1500 vaccinations each year at the Birmingham Dispensary.

\section{Childhood palsy}

Darwall's work also stands out as an early treatise on childhood paralysis-palsy.

"Palsy is unfortunately much more frequent among very young children than is commonly supposed, and in the majority of cases it is incurable, though in most instances, it may be considerably relieved". (p. 153) 12

Additionally, Darwall provides an early description of stroke in childhood.

"The first attack of palsy in infants does not always attract immediate notice, and several days sometimes elapse before the nurse is aware that the use of the limbs are lost. It happens often without any symptom of disordered health, and often when in other respects the child is perfectly well.

It is sometimes the result of convulsion.

With respect to the cause of the palsy it may be temporary or permanent: but the latter is most common. Of the state of the brain in children I can say nothing: I have never known a case terminate fatally". (p. 154) ${ }^{12}$

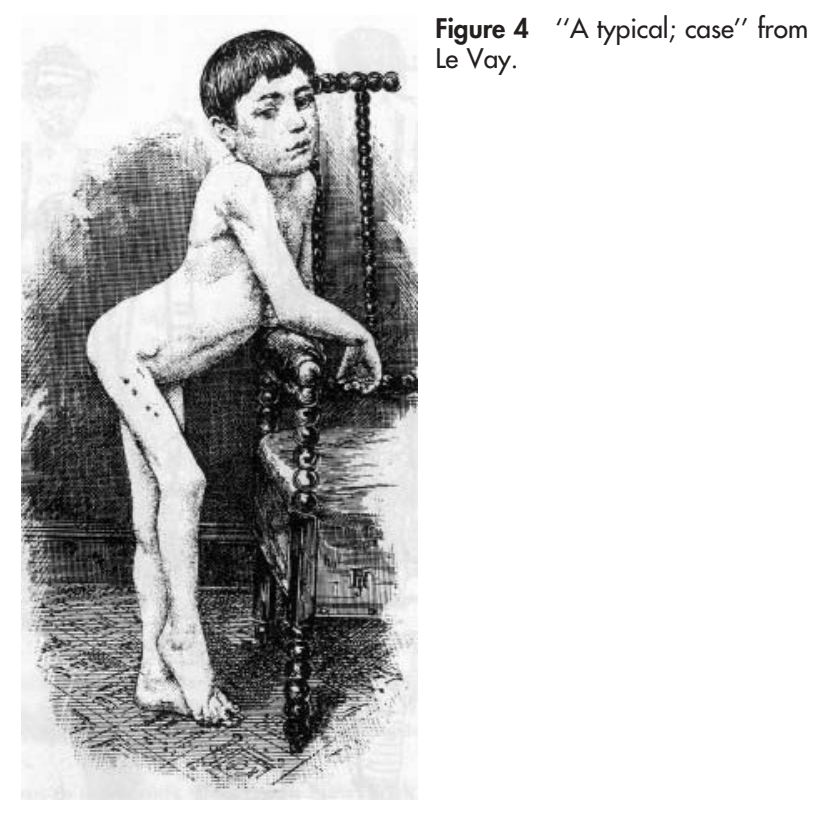

His recommended treatment involved powder of jalap, calamol, and rubbing. He advocated rubbing of the affected limb "frequently and constantly is the most effectual: it appears to equalise the circulation and in this way to relieve the brain". If the paralysis was incomplete he encouraged using the affected limb. Darwall was sceptical of the use of leg irons although he recognised their use when "the limb becomes deformed from the irregular action of the muscles". He generally believed that they gave little benefit, being "a substitute for, rather than an assistant for muscular action". He cites one case "where the loss of power in the limbs which had been in some measure regained, was the consequence of wearing irons" and leg irons as a substitute for muscles. His contempt for galvanism has already been described.

\section{Respiratory disorders}

Darwall also wrote a chapter on respiration, respiratory disorders having accounted for the majority of cases at the Dispensary where he served in these years. ${ }^{17}$ In particular, he describes how catarrh or common cold is usually mild in adults, but "not infrequently productive in infants of fatal consequences" (p. 158). ${ }^{12}$ He describes its symptoms and how much benefit can be derived from purging using "neutral salts" or, if the child has "much heat about the nose", recommends leeches. This treatment was also to be used for croup. However, his opinion of steam inhalation is scathing:

"No advantage will be experienced from directing steam up the nostrils: it may even prove injurious, by producing additional irritation". (p. 160) ${ }^{12}$

\section{Pneumonia and croup}

In these sections, Darwall addresses respiratory disease and includes case histories with some postmortem discussion. Bleedings and emetics were still recommended, their use having been rational given the understanding of medicine in the early nineteenth century, though the former practice was losing favour among some members of the medical profession. Nevertheless, while Darwall had learned the importance of observation and pathological anatomy while a medical student, his therapeutic regime was slower to change and shared many similarities with those of a bygone age, even though measures, such as blood-letting, were recommended for different reasons.

"In the treatment of cough, very many and different remedies have in time past been proposed. They are now, however, almost confined to two, viz blood-letting and calomel, and perhaps in the latter stages emetics may be recommended. The object of bleeding is to prevent inflammation and thus to prevent also the formation of the false membrane [as opposed to balancing the humours, as practiced formerly]. For this purpose leeches, cupping, or general blood-letting, must be practised according to the age of the child"'. (p. 171) $)^{12}$

Neither does Darwall shirk from necessary vigour in his blood-letting, faith in which began to die among English practitioners only a few years after Darwall's own death:

"In children under 2 years of age it does not often happen that depletion can occur in any other way than by means of leeches. Occasionally however it is possible to open the jugular vein: and this mode of depleting is always to be preferred either to leeches or cupping, when it can be practised ... (for croup). It is useless to bleed slightly-it should always be practised so as to affect the system: 
either the symptoms should yield, or the bleeding should be continued to faintness. But bleeding, I repeat is only applicable to the first stage of croup, and before the factitious membrane is present. When it is formed it can be of no service but it may be injurious by diminishing the strength". (p. 171) $)^{12}$

\section{"Hooping cough"}

Darwall notes that whooping cough seldom affected a child twice and comments on the different European thoughts regarding its origin, with the French being "in complete opposition" to the English belief that the condition is infectious (p. 174). Darwall's own conviction was that "prudence certainly dictates that we should act as though the English opinion were positively certain. Children should not be wantonly exposed even to the chance of being infected" (p. 175). ${ }^{12}$ He then, as expected, presents a detailed clinical history with a description of the pathology observed in specific cases. His treatment includes a thorough evacuation of the bowels (pp. 180-1), "friction over the chest and spine, even when practiced without any liniment, but, with the addition of an opiate embrocation is highly serviceable") which is rubbed in hourly "unless the opiate should seem to induce any thing like stupor".

He then discusses the different medicines at that time advocated "to alleviate the cough or to correct the state of the stomach or both". Accepted treatments discussed include ipecacuanhae, camphor, and quinine (although Darwall admits he has no clinical experience in this) including leeches and emetics. He mentions that, like as in "every other obstinate disorder" there are a variety of other treatments "specifics, all of which, probably are sometimes useful, and from which at others, no benefit whatever is derived" (p. 184). In concluding the section, he advocates a change of air as being highly beneficial in the latter part of the disease.

Finally, the work also contains much advice of a nonmedical nature. For example, while advocating early learning, Darwall stresses such instruction be converted into an amusement. Furthermore, he suggests mothers exercise children's bodies and not just their minds. ${ }^{21}$ Finally, Darwall encourages parents to impart Christian teachings. One cannot help but imagine that these passages, above all others, come very close to being autobiographical.

\section{THE FINAL YEARS}

In 1831, Darwall achieved what might have been the greatest success in a short medical career when he was finally appointed physician to the General Hospital, Birmingham (fig 5). Rarely leaving town in these years, one can only imagine he was very committed to his patients. He also continued to devote much time to medical education, instituting clinical lectures, as he felt many of his fellow practitioners neglected morbid anatomy. As a result, besides being one of the hospital's four honorary medical practitioners, he undertook several postmortem examinations, to which his publications occasionally refer. Well aware of the dangers practitioners faced in the dead room, which were identified in his work on occupational health, Darwall, quite ironically, predicted his own death. His hospital book of 30 July 1833 contains a final entry, which was presumably made while examining his last patient's body: "Head Medullary Sarcoma of the Bronchial Glands. Left lung had been filled with pus, left pleura inflamed, as was pericardium". ${ }^{22}$ After completing this final, fateful investigation, Darwall's health deteriorated and he died 11 days later. He was buried in the family vault at Christ Church, Birmingham.

His obituary clearly emphasised the belief that a very promising medical career had been cut short: "of no more member of the medical profession might it have been more

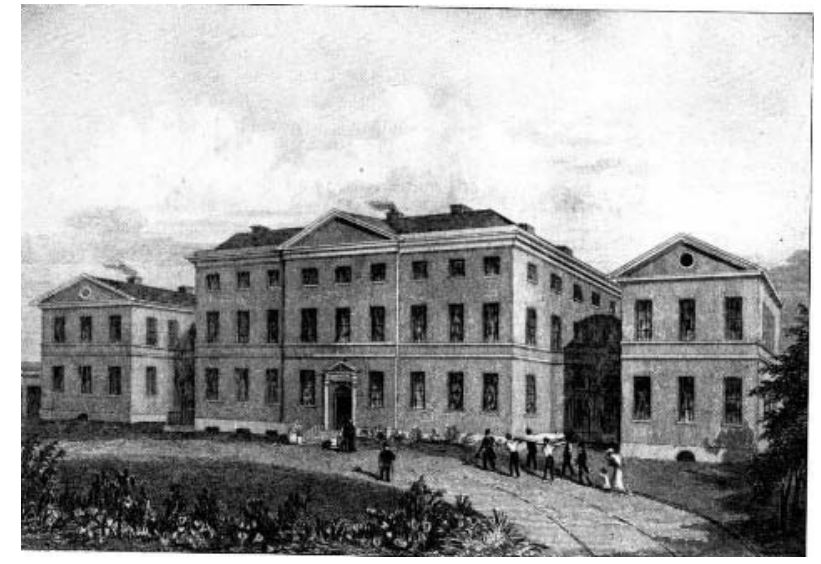

Figure 5 Birmingham General Hospital, 1829 (private collection).

confidently predicted that he would enjoy the most extensive fame and realise an ample fortune" ${ }^{\prime 23}$

\section{CONCLUSION}

After his death, Darwall's name and words completely disappeared from the medical literature. His contributions are not cited by Sigmund Freud in his 1897 treatise on Infantile Hemiplegias or by G. F. Stills in his History of paediatrics. Working a quarter century before West and the establishment of Great Ormond Street Hospital (1852), not to mention the founder of Birmingham's own children's hospital (established in 1861), Thomas Heslop, Darwall's tragically early death extinguished an astute voice that could have ranked among the greats of nineteenth century child health medicine. Instead his legacy only hints at this important transitional period in modern medicine. For example, his approach to medicine relied on much clinical work and an understanding of the signs of pathological anatomy, ideas that emerged in France, but were picked up only hesitantly in England. His therapeutics, on the other hand, appear hardly to differ from the armamentarium available to practitioners working in an age of symptoms and humors. While many of his contemporaries would survive to see these ideas unify in an age of germs, Darwall was less fortunate, falling victim, like so many young doctors in these years, to the as yet undetected seeds of disease.

"I cannot but hope that the few hints now thrown out may in future prevent this in some degree: at any rate they who practise their profession, not merely that they may accumulate wealth, but that they may accumulate it honestly, will do well to consider, that by the attention and trouble which such patients cost them, they will save their profession from that degradation into which, from that fraudulent and empirical arts that are practised by too many of its members, it is daily sinking"

\section{ACKNOWLEGEMENTS}

We would like to thank the Centre for the History of Medicine, Medical School, Birmingham, and the Cripps Postgraduate Medical Centre, Northampton General Hospital for their support.

\section{Authors' affiliations}

A N Williams, Northampton General Hospital, UK

J Reinarz, Centre for the History of Medicine, University of Birmingham, UK 


\section{REFERENCES}

1 Meikeljohn A. John Darwall, M.D. (1796-1833) and "Diseases of Artisans". $\mathrm{BrJ}$ Ind Med 1956;13(2):142-51.

2 Conolly J. A biographical memoir of the late Dr John Darwall of Birmingham. London: Sherwood, Gilbert, and Piper, 1834:4.

3 Meikeljohn A. John Darwall, M.D. (1796-1833) and "Diseases of Artisans". Br J Ind Med 1956;13(2):142.

4 Conolly J. A biographical memoir of the late Dr John Darwall of Birmingham. London: Sherwood, Gilbert, and Piper, 1834:28.

5 Porter R. The greatest benefit to mankind. London: Harper Collins, 1997:311.

6 Darwall J. Cases of ovarian or encysted dropsy. Midland Medical and Surgical Reporter 1828-9;1:402.

7 Darwall J. Cases of ovarian of encysted dropsy. Midland Medical and Surgical Reporter 1828-9;1:402.

8 Darwall J. Observations upon some forms of spinal and cerebral irritation. Midland Medical and Surgical Reporter 1828-9;1.

9 Conolly J. A biographical memoir of the late Dr John Darwall of Birmingham. London: Sherwood, Gilbert, and Piper, 1834:6.

10 Conolly J. A biographical memoir of the late Dr John Darwall of Birmingham. London: Sherwood, Gilbert, and Piper, 1834:47.

11 Conolly J. A biographical memoir of the late Dr John Darwall of Birmingham. London: Sherwood, Gilbert, and Piper, 1834:49.
12 Darwall J. Plain instructions for the management of infants. London: Whittaker, Treacher and Arnot, 1830:vi.

13 Darwall J. Plain instructions for the management of infants. London: Whittaker, Treacher and Arnot, 1830:vii.

14 Darwall J. Plain instructions for the management of infants. London: Whittaker, Treacher and Arnot, 1830:6.

15 Cadogan W. An Essay upon nursing and the management of children, from their birth to three years of age. London: J Roberts, 1749.

16 Fildes V. Breast, bottle and babies. Edinburgh: Edinburgh University Press, 1986:122.

17 Lomax E. Small and special: the development of hospitals for children in Victorian Britain. London: Wellcome Institute for the History of Medicine, 1996:17.

18 Birmingham Medical School. Birmingham Dispensary, Annual Report 1830.

19 Risse G. Hospital life in enlightenment Scotland. Cambridge: Cambridge University Press, 1986:240.

20 Darwall J. Plain instructions for the management of infants. London: Whittaker, Treacher and Arnot, 1830:25-6.

21 Darwall J. Plain instructions for the management of infants. London: Whittaker, Treacher and Arnot, 1830:xvi.

22 Conolly J. A biographical memoir of the late Dr John Darwall of Birmingham. London: Sherwood, Gillbert, and Piper, 1834:54.

23 Anon. Warwickshire Advertiser, 17 August 1833.

ARCHIVIST.

\section{Autologous stem cell transplantation for juvenile idiopathic arthritis}

B tween $5 \%$ and $10 \%$ of children with systemic or polyarticular onset juvenile idiopathic arthritis (JIA) do not response adequately to treatment with non-steroidal antiinflammatory drugs and immunosuppressive drugs such as methotrexate and corticosteroids. Among such children severe joint destruction, growth retardation, drug toxicity, and psychological distress are common and some (around $2-4 \%$ of children with systemic onset disease) die of the disease. The main causes of death are drug toxicity, infection, amyloidosis, and the later development of diseases such as systemic lupus erythematosus or scleroderma. Anti-tumour necrosis factor (anti-TNF) treatment has proved effective for children with polyarticular onset disease but less so in those with active systemic onset disease.

If standard immunosuppression is effective treatment for most children with JIA then perhaps intense immunosuppression and autologous stem cell transplantation (ASCT) would be effective for children with more severe, refractory disease? Since 1997, 41 children in Europe are known to have had ASCT for refractory polyarticular or systemic onset JIA. The findings on follow up of 34 of these children at nine European centres have been reported (IM de Kleer and colleagues. Annals of Rheumatic Diseases 2004;63:1318-26).

There were 19 boys and 15 girls. Their mean age at disease onset was 3 years 11 months (range 8 months to 10 years 2 months) and at ASCT 9 years 5 months (range 4 years 3 months to 18 years 3 months). Twenty-nine had systemic onset and five polyarticular onset JIA. Ten had been treated unsuccessfully with anti-TNF therapy. All had delayed growth and 27 had osteoporosis. Other evidence of drug toxicity included hypertension, myelosuppression, vertebral fractures, avascular necrosis of the femoral head, and cataracts.

All 34 children had successful engraftment with full haematological recovery. Three children died as a result of transplantation, at 10 days, 18 days, and 4 months post ASCT. Posttransplant morbidity included infection (24 children, 6 with septicaemia), varicellazoster virus infection (11 patients at 3-18 months), and cytomegalovirus infection (6 reactivation, 1 primary, at $1-12$ months). The mean duration of follow up at the time of reporting was 2 years and 4 months. Eighteen children had complete drug-free remission of their disease, six had a partial response, and seven had no lasting response. Among the patients who eventually achieved complete remission there were five whose disease got worse when prednisone dosage was tapered at 3-6 months. These flare-ups responded to standard management. The seven patients classified as non-responders all improved soon after ASCT but their JIA relapsed after 3-17 months. The six patients with a partial response were more responsive to standard treatments after transplantation. Two achieved 30\% improvement, three $50 \%$, and one $70 \%$. Wellbeing and pain scores generally improved greatly in the first 3-6 months and improvement was maintained.

ASCT induced drug-free remission in over half of these children with severe, refractory JIA and substantial improvement in another six of the 34. Marked increase in general wellbeing was noticeable. Three children died and posttransplant morbidity was common. It is proposed that in future total body irradiation will not be used as part of the conditioning regimen and antiviral drugs and intravenous immunoglobulin will be given prophylactically until the CD4+T cell count is normal. 